\title{
Ceftriaxone and ciprofloxacin restriction in an intensive care unit: less incidence of Acinetobacter spp. and improved susceptibility of Pseudomonas aeruginosa
}

\author{
Julio César Medina Presentado, ${ }^{1}$ Daniela Paciel López, ${ }^{2}$ \\ Maximiliano Berro Castiglioni, ${ }^{2}$ and Jorge Gerez $^{2}$
}

Suggested citation Medina Presentado JC, Paciel López D, Berro Castiglioni M, Gerez J. Ceftriaxone and ciprofloxacin restriction in an intensive care unit: less incidence of Acinetobacter spp. and improved susceptibility of Pseudomonas aeruginosa. Rev Panam Salud Publica. 2011;30(6):603-9.

ABSTRACT Objective. To determine whether restricting the use of ceftriaxone and ciprofloxacin could significantly reduce colonization and infection with resistant Gram-negative bacilli ( $r$-GNB). Methods. A two-phase prospective study (beforelafter design) was conducted in an intensive care unit in two time periods (2004-2006). During phase 1, there was no antibiotic restriction. During phase 2, use of ceftriaxone or ciprofloxacin was restricted.

Results. A total of 200 patients were prospectively evaluated. In phase 2, the use of ceftriaxone was reduced by $93.6 \%(\mathrm{P}=0.0001)$ and that of ciprofloxacin by $65.1 \%$ $(\mathrm{P}=0.041)$, accompanied by a $113.8 \%$ increase in use of ampicillin-sulbactam $(\mathrm{P}=0.002)$. During phase 1, 48 GNB were isolated [37 r-GNB (77.1\%) and 11 non-r-GNB (22.9\%)], compared with a total of 64 during phase 2 [27 $r$-GNB (42.2\%) and 37 non-r-GNB (57.8\%)] $(\mathrm{P}=0.0002)$. Acinetobacter spp. was isolated 13 times during phase 1 and 3 times in phase $2(\mathrm{P}=0.0018)$. The susceptibility of Pseudomonas aeruginosa to ciprofloxacin increased from $40.0 \%$ in phase 1 to $100.0 \%$ in phase $2(\mathrm{P}=0.0108)$.

Conclusions. Restriction of ceftriaxone and ciprofloxacin reduced colonization by Acinetobacter spp. and improved the susceptibility profile of $\mathrm{P}$. aeruginosa.

Key words Drug resistance, multiple; Acinetobacter baumannii; Pseudomonas aeruginosa; antibacterial agents; Uruguay.

Infections by resistant Gram-negative bacilli (r-GNB) in the nosocomial environment have been highlighted as particularly problematic for clinical practice $(1,2)$. This problem has been described for Acinetobacter baumannii (3), Pseudomonas aeruginosa (4), Klebsiella pneumoniae

\footnotetext{
Cátedra de Enfermedades Infecciosas, Facultad de Medicina, Universidad de la República, Montevideo, Uruguay. Send correspondence to: Julio César Medina Presentado, jcmedina1@gmail.com, jcmedina@fmed.edu.uy

2 Unidad de Cuidados Intensivos, Hospital Policial, Montevideo, Uruguay.
}

(5), and Enterobacter cloacae $(6,7)$. Epidemic and endemic situations due to $r-G N B$ are increasingly recognized in Latin American countries (8-10).

The resistant strains are generally isolated after wide spectrum cephalosporin treatment because they generate strain selection pressure (11-13). This problem is particularly important in intensive care units. Vignoli et al. (14) documented that the administration of oxyiminocephalosporins was associated with the selection of resistant strains of Entero- bactereaceae in the fecal flora. Previous use of ceftriaxone and ciprofloxacin was recently identified as a significant independent predictor for the development of ventilator-associated pneumonia with Acinetobacter spp. (15).

The importance of patients infected and colonized by r-GNB is reflected in the recommendation to isolate them as an effective means to decrease crosscolonization $(16,17)$. However, this measure is not enough to limit the increased incidence of r-GNB. Other strategies, 
such as antimicrobial rotation (18-20) and restriction (21) policies, have been developed for this purpose. These strategies have not been evaluated in great detail in the South America region. The increased isolation of r-GNB, particularly Acinetobacter spp. (15) and Pseudomonas aeruginosa in the intensive care unit at Hospital Policial, Montevideo, Uruguay, motivated this study in order to determine whether restricting the use of ceftriaxone and ciprofloxacin could result in a significant reduction in the incidence of r-GNB colonization and infection in critically ill patients. The secondary objective was to test whether such a change in strategy would improve the susceptibility pattern of any microorganism.

\section{MATERIALS AND METHODS}

\section{Study design}

A two-phase prospective study (before/after design) was conducted in the intensive care unit of Hospital Policial, Montevideo, Uruguay, within two periods of time (2004-2006). All patients admitted to the intensive care unit for 48 hours or more were successively included. During phase 1, clinicians could freely prescribe antibiotics like ceftriaxone and ciprofloxacin when they suspected either community or early nosocomial infection. During phase 2, both antibiotics were restricted. To achieve a successful restriction, staff were educated for 2 months before the beginning of the second phase; in addition, researchers (J.C.M.P. and J.G.) constantly monitored antibiotic indications. When a patient had a suspected community or early nosocomial infection, the clinician used ampicillin-sulbactam instead of ceftriaxone and aminoglycoside alone or associated with another antibiotic instead of ciprofloxacin. The staff were in charge of the prescription and duration of the antibiotic therapy. However, approval by an investigator (J.C.M.P. or J.G.) was required before empirical or definitive use of ceftriaxone and ciprofloxacin, with the exception of the use of ceftriaxone for acute bacterial meningitis.

Cefepime, antipseudomonal penicillin, and piperacillin-tazobactam were not available for use in the intensive care unit.

\section{Study location}

The study was conducted at a university-affiliated tertiary-care public hospi- tal: Hospital Policial (241 beds) in Montevideo, Uruguay. The intensive care unit is an eight-bed general intensive care unit, with air-conditioned closed units without negative pressure.

\section{Patients}

All patients admitted to the intensive care unit from 1 May 2004 to 28 February 2005 were eligible for phase 1 of the study; phase 2 included patients admitted from 1 May 2005 to 28 February 2006. Standard care for management of infections was maintained in both periods. Data are presented so that individual patients cannot be identified.

\section{Data collection}

Patients were followed up daily until discharge from the intensive care unit. The recorded variables were: gender, age, severity of underlying illness (22), previous medical condition (23), diagnosis at admission, length of stay in the intensive care unit, mortality, invasive procedures, infection and colonization focuses, type of pathogens, and antibiotic resistance profile. The number of hours of nursing was recorded in each phase and is expressed as hours of nursing per 1000 patient-days. Antibiotic use was reviewed for each patient and was recorded as total grams of the drug and was then converted to defined daily doses per 1000 patient-days, in accordance with the World Health Organization recommendation. Only the expenditure for drugs that were administered intravenously was analyzed $(24,25)$.

\section{Microbiology}

Cultures were obtained according to clinical indications. One isolate was recorded per body site per patient. All isolates were identified by standard microbiological methods, and susceptibility testing was performed according to international guidelines (26).

The susceptibility of GNB to ceftriaxone, ceftazidime, ciprofloxacin, imipenem, meropenem, gentamicin, amikacin, and ampicillin-sulbactam was evaluated.

\section{Definitions}

Colonization or infection was determined by criteria of the Centers for Disease Control and Prevention (Atlanta,
Georgia, United States of America) (27). An infection acquired in the intensive care unit was defined as an infection that was not present at admission and that developed after a stay of 48 hours.

The diagnosis of ventilator-associated pneumonia was determined according to previously established definitions (15, 28-30).

r-GNB were defined as any GNB resistant to one or more of the following: all aminoglycosides, all third-generation cephalosporins, and all carbapenems (18).

\section{Statistical analysis}

Continuous variables were compared by using Student's $t$-test and a chi-square test or Fisher's exact test to compare categorical variables. All comparisons were unpaired and all tests of significance were twotailed. A $P$ value $<0.05$ was considered statistically significant. In order to evaluate the day of resistant GNB colonization, a Kaplan-Maier curve was prepared.

\section{RESULTS}

\section{Patients}

A total of 200 patients were prospectively evaluated ( $n=100$ in each phase). A comparison of clinical and demographic characteristics, mortality, and stay in the intensive care unit during both periods showed no significant differences other than the diagnosis at admission of nontraumatic acute brain injury at $33.0 \%$ in phase 1 versus $18.0 \%$ in phase $2(P=$ 0.02 ) (Table 1). No significant differences were registered between phases in relation to invasive procedures and days of device usage (Table 2).

\section{Changes in antibiotic use}

During phase 2, the use of ceftriaxone declined by $93.6 \%(P=0.0001)$, the final consumption of ciprofloxacin decreased by $65.0 \%(P=0.041)$, and the use of ampicillin-sulbactam increased by $113.8 \%$ ( $P=$ $0.002)$. Although an increase in the use of carbapenems by $12.7 \%$ and aminoglycoside by $30.7 \%$ was also seen, the findings were not statistically significant (Table 3).

\section{Incidence of infection and colonization}

Nosocomial infection device-related rates, like ventilator-associated pneumo- 
TABLE 1. Demographic and clinical characteristics of patients without and with restriction of antimicrobials, intensive care unit, Hospital Policial, Montevideo, Uruguay, 2004-2006

\begin{tabular}{|c|c|c|c|}
\hline Characteristic & Phase $1^{a}$ & Phase $2^{b}$ & $P$ value \\
\hline Male, \% & 50.0 & 46.0 & 0.67 \\
\hline Female, \% & 50.0 & 54.0 & \\
\hline \multicolumn{4}{|l|}{ Years of age } \\
\hline Mean \pm SD & $62.8 \pm 13.7$ & $56.6 \pm 19.8$ & 0.07 \\
\hline Median (interquartile range) & $64(55.7-73)$ & $61(42.2-72)$ & \\
\hline \multicolumn{4}{|l|}{ APACHE II score } \\
\hline Mean \pm SD & $21.6 \pm 7.7$ & $21.3 \pm 6.6$ & 0.79 \\
\hline Median (interquartile range) & $21(17-25.7)$ & $21(17-26)$ & \\
\hline \multicolumn{4}{|l|}{ McCabe and Jackson (23) criteria } \\
\hline Rapidly fatal disease, \% & 0.0 & 1.0 & 0.487 \\
\hline Ultimately fatal disease, \% & 23.0 & 19.0 & \\
\hline Nonfatal disease, $\%$ & 77.0 & 80.0 & \\
\hline \multicolumn{4}{|l|}{ Preexisting comorbidity } \\
\hline Chronic alcoholism, \% & 13.0 & 20.0 & 0.25 \\
\hline Received corticosteroids, \% & 5.0 & 8.0 & 0.56 \\
\hline Hospitalized 3 months before, $\%$ & 20.0 & 19.0 & 1.0 \\
\hline Diabetes, \% & 22.0 & 23.0 & 1.0 \\
\hline Cardiovascular disease, $\%$ & 10.0 & 21.0 & 0.49 \\
\hline Liver disease, \% & 2.0 & 5.0 & 0.44 \\
\hline \multicolumn{4}{|l|}{ Diagnosis at admission } \\
\hline Nontraumatic ABI, \% & 33.0 & 18.0 & 0.02 \\
\hline Severe CAP, $\%$ & 8.0 & 12.0 & 0.48 \\
\hline COPD exacerbation, $\%$ & 1.0 & 2.0 & 1.0 \\
\hline Severe trauma, $\%$ & 6.0 & 14.0 & 0.09 \\
\hline Severe sepsis, \% & 15.0 & 7.0 & 0.11 \\
\hline Cardiovascular disease, $\%$ & 11.0 & 14.0 & 0.66 \\
\hline Cardiac arrest, \% & 3.0 & 1.0 & 0.62 \\
\hline Thoraco-abdominal surgery, \% & 10.0 & 14.0 & 0.51 \\
\hline Miscellaneous, \% & 13.0 & 18.0 & 0.14 \\
\hline All-cause death, $\%$ & 38.0 & 35.0 & 0.76 \\
\hline Days in ICU, mean \pm SD & $11.2 \pm 10.1$ & $10.0 \pm 9.2$ & 0.41 \\
\hline
\end{tabular}

Note: SD: standard deviation, APACHE II: Acute Physiology and Chronic Health Evaluation II, ABI: acute brain injury, CAP: community acquired pneumonia, COPD: chronic obstructive pulmonary disease, ICU: intensive care unit. ${ }^{a}$ Without restriction, 1 May 2004 to 28 February $2005(n=100)$.

${ }^{b}$ With restriction, 1 May 2005 to 28 February $2006(n=100)$.

TABLE 2. Invasive procedures performed on patients without and with restriction of antimicrobials, intensive care unit, Hospital Policial, Montevideo, Uruguay, 2004-2006

\begin{tabular}{lccc}
\hline \multicolumn{1}{c}{ Variable } & Phase $1^{\mathrm{a}}$ & Phase $2^{\mathrm{b}}$ & $P$ value \\
\hline Invasive mechanical ventilation, \% & 80.0 & 84.0 & 0.46 \\
Days of invasive mechanical ventilation, mean \pm SD & $9.3 \pm 9.8$ & $9.1 \pm 9.9$ & 0.89 \\
Reintubation, \% & 12.0 & 10.0 & 0.65 \\
Tracheotomy, \% & 18.0 & 11.0 & 0.16 \\
Urinary tract catheterization, \% & 91.0 & 97.0 & 0.07 \\
Days of urinary tract catheterization, mean \pm SD & $10.5 \pm 9.8$ & $10.0 \pm 9.3$ & 0.72 \\
Central vein catheterization, \% & 89.0 & 96.0 & 0.06 \\
Days of central vein catheterization, mean \pm SD & $8.4 \pm 6.2$ & $7.1 \pm 5.4$ & 0.058 \\
\hline
\end{tabular}

Note: SD: standard deviation.

a Without restriction, 1 May 12004 to 28 February 2005

${ }^{b}$ With restriction, 1 May 2005 to 28 February 2006.

nia, catheter-related urinary tract infection, and central venous catheter-related bloodstream infections, were 19.2, 10.4, and 1.9 episodes per 1000 device days for phase 1 and 23.2, 10.1, and 2.5 for phase 2, respectively. The rate of other infections acquired in the intensive care unit was 5.3 per 1000 patients/day in phase 1 as opposed to 12.9 per 1000 patients/day in phase 2 .

During the first half of phase 1,8 of 26 patients acquired at least one nosocomial infection, while 21 of 36 acquired at least one infection $(P=0.04)$ in the first half of phase 2. Average nursing hours per 1000 patients/day were $2187 \pm 178$ and $1986 \pm 44$ in the first half of phase 1 and 2 , respectively $(P=0.02)$.

The day-by-day probability of remaining free of $r-G N B$ was calculated for both phases with the Kaplan-Maier estimate. There was a nonsignificant tendency for patients in phase 2 to be colonized by r-GNB at a later period (log rank 0.7698) (Figure 1).

\section{Changes in GNB antibiotic susceptibility}

In phase 1, 48 GNB were isolated [37 r-GNB (77.1\%) and 11 non-r-GNB (22.9\%)], whereas 64 GNB were isolated in phase 2 [27 r-GNB (42.2\%) and 37 nonr-GNB (57.8\%)] $(P=0.0002)$.

During phase 1, Acinetobacter spp. was isolated 13 times from a total of $48 \mathrm{GNB}$, but only 3 Acinetobacter spp. from a total of 64 GNB $(P=0.0018)$ were isolated in phase 2. An increase in Klebsiella spp. and other GNB was observed in phase 2 $(P=0.0149$ and $P=0.0415$, respectively) (Table 4).

Table 4 shows the total GNB distribution and its resistance profile. Table 5 shows the distribution of r-GNB isolated from colonizations and infections. With regard to the resistance profile of $P$. aeruginosa during phase $1,60.0 \%$ were resistant to ciprofloxacin; in phase 2, none of the isolated $P$. aeruginosa was resistant to this antimicrobial $(P=0.0108)$.

A total of 22 Enterobacteriaceae (Enterobacter spp., Escherichia coli, Proteus spp., Klebsiella spp.) were isolated in phase 1, and 39 were isolated in phase 2. Enterobacter went from representing $36.3 \%$ of the Enterobacteriaceae in phase 1 to representing $12.8 \%$ in phase $2(P=$ 0.049), while Proteus spp. plus Klebsiella spp. increased from $22.7 \%$ in phase 1 to $61.5 \%$ in phase $2(P=0.0069)$.

There was no significant variability in the resistance of GNB to ceftazidime, carpabapenemes, aminoglycosides, and ampicillin-sulbactam.

\section{DISCUSSION}

The most important finding of this study is that the restriction of ceftriaxone and ciprofloxacin positively affected the ecology of the intensive care unit. $r-G N B$ isolations declined significantly 
TABLE 3. Change in antibiotic use without and with restriction of antimicrobials, intensive care unit, Hospital Policial, Montevideo, Uruguay, 2004-2006

\begin{tabular}{|c|c|c|c|c|}
\hline \multirow[b]{2}{*}{ Antibiotic } & \multicolumn{2}{|c|}{$\begin{array}{l}\text { Defined daily doses } \\
\text { per } 1000 \text { patient-days }\end{array}$} & \multirow[b]{2}{*}{ Change, \% } & \multirow[b]{2}{*}{$P$ value } \\
\hline & Phase $1^{a}$ & Phase $2^{b}$ & & \\
\hline All third-generation cephalosporins & 166.3 & 66.5 & -60.2 & 0.02 \\
\hline Ceftriaxone & 111.1 & 6.9 & -93.6 & 0.0001 \\
\hline Cefotaxime & 8.0 & 6.9 & -12.5 & 0.48 \\
\hline Ceftazidime & 47.3 & 52.6 & +10.6 & 0.29 \\
\hline Ciprofloxacin & 149.9 & 52.4 & -65.1 & 0.041 \\
\hline Carbapenem & 126.2 & 142.8 & +12.7 & 0.065 \\
\hline Ampicillin-sulbactam & 382.2 & 817.5 & +113.8 & 0.002 \\
\hline Aminoglycosides & 117.0 & 153.3 & +30.7 & 0.055 \\
\hline Total & 1108.1 & 1298.8 & +17.1 & 0.08 \\
\hline
\end{tabular}

a Without restriction, 1 May 2004 to 28 February 2005.

${ }^{b}$ With restriction, 1 May 2005 to 28 February 2006.

from $77.1 \%$ in phase 1 to $42.2 \%$ in phase 2. However, a more detailed analysis shows that the greatest impact in the reduction of r-GNB was in colonizations. It is known that colonized patients are an important source of r-GNB for later dissemination and possible infection in the intensive care unit, which is why it has been recommended that patients colonized with r-GNB be isolated as an effective means to control patient-topatient transmission $(16,17)$. A clinical and molecular typification study (31) showed that $64.0 \%$ of the strains of mul-

FIGURE 1. Day-by-day probability of remaining free of infections and colonization with resistant Gram-negative bacilli in patients without (phase 1) and with (phase 2) restriction of antimicrobials, intensive care unit, Hospital Policial, Montevideo, Uruguay, 2004-2006 (log rank 0.7698)

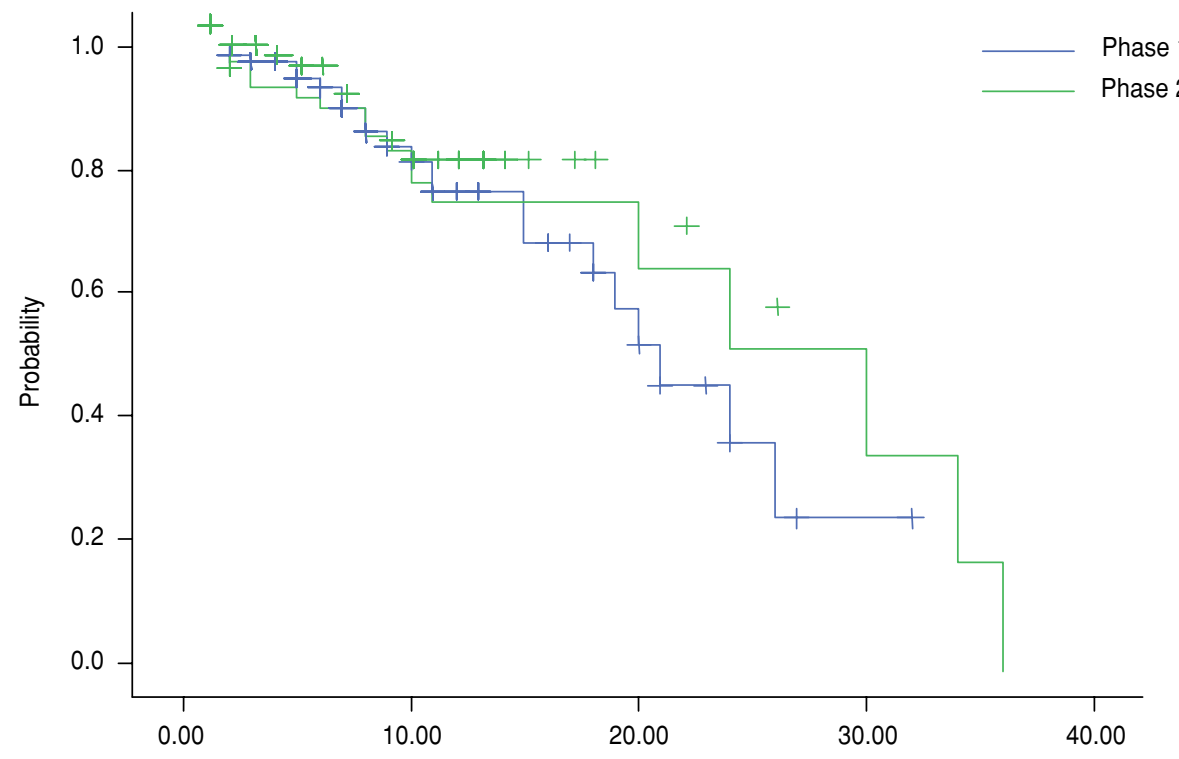

Day of infection and colonization by resistant Gram-negative bacilli croorganism. This study achieved both a decreased incidence in a particular pathogen and a change in the susceptibility profile of another r-GNB.

Acinetobacter spp. was significantly reduced in phase 2 , leading to the notion that it is directly related to the restriction of ceftriaxone and ciprofloxacin. A prospective study has already demonstrated that previous use of these antimicrobials is independently associated with the development of ventilator-associated pneumonia caused by Acinetobacter spp. (15). In the case of ceftriaxone, the explanation could be that it is mainly excreted through the bile (34, $35)$, causing a rapid colonization of the digestive tract by Acinetobacter spp. (36). Gruson et al. achieved reduction of a particular microorganism, like Burkholderia cepacia, by restricting ceftazidime and ciprofloxacin (19).

An impact on the susceptibility profile was seen in $P$. aeruginosa in relation to ciprofloxacin, in which susceptibility increased from $40.0 \%$ in phase 1 to $100.0 \%$ in phase 2. Aubert et al. documented a decrease in resistant strains from $71.3 \%$ in the prerestriction period to $52.4 \%$ in the postrestriction period (37) Neuhauser et al. (38) and Friedland et al. (39) documented the increasing incidence of ciprofloxacin resistance among GNB associated with increased use of fluoroquinolones. The benefit of recovering susceptibility lies in the possibility of other therapeutic options for P. aeruginosa. It has been shown that adequate empirical treatments are associated with less morbidity and mortality (40), so if one must empirically cover GNB with a less restricted susceptibility profile, the possibility of performing an adequate empirical therapy is greater (41).

As far as Enterobacteriaceae are concerned, there has been an increase in phase 2 that can be attributed to a smaller nursing staff during this phase $(42,43)$, considering that other variables like demographical data, severity, and invasive procedures were similar. There was a significant decrease in Enterobacter spp. and a significant increase in Klebsiella spp. and Proteus spp. The explanation for this phenomenon could be related to two events that occurred during this research. The decrease in Enterobacter spp. could be directly related to the reduced use of oxyiminocephalosporins. Vignoli and others (14, 
TABLE 4. Resistance of isolated Gram-negative bacilli without and with restriction of antimicrobials, intensive care unit, Hospital Policial, Montevideo, Uruguay, 2004-2006

\begin{tabular}{|c|c|c|c|c|c|c|c|c|c|}
\hline \multirow[b]{2}{*}{ Bacillus } & \multirow{2}{*}{$\begin{array}{l}\text { No. of } \\
\text { strains }\end{array}$} & \multicolumn{8}{|c|}{ Percent resistance to: } \\
\hline & & CRO & $\mathrm{CAZ}$ & CIP & IMP & MER & GEN & AK & AM/SB \\
\hline \multicolumn{10}{|c|}{ Pseudomonas aeruginosa } \\
\hline Phase $1^{\mathrm{a}}$ & 10 & $\ldots$ & 0.0 & 60.0 & 0.0 & 0.0 & 70.0 & 0.0 & $\ldots$ \\
\hline Phase $2^{b}$ & 9 & $\ldots$ & 25.0 & $0.0^{\mathrm{a}}$ & 11.1 & 11.1 & 44.4 & 0.0 & $\ldots$ \\
\hline \multicolumn{10}{|c|}{ Acinetobacter species } \\
\hline Phase $1^{\mathrm{a}}$ & 13 & 100.0 & 100.0 & 100.0 & 0.0 & 33.3 & 50.0 & 91.7 & 91.7 \\
\hline Phase $2^{b}$ & $3^{c}$ & 100.0 & 100.0 & 100.0 & 0.0 & 0.0 & 33.3 & 100.0 & 100.0 \\
\hline \multicolumn{10}{|c|}{ Enterobacter species } \\
\hline Phase $1^{\mathrm{a}}$ & 8 & 0.0 & 100.0 & 100.0 & 0.0 & 0.0 & 71.4 & 85.7 & 100.0 \\
\hline Phase $2^{b}$ & 5 & 50.0 & 75.0 & 75.0 & 0.0 & 0.0 & 71.4 & $0.0^{\mathrm{a}}$ & 75.0 \\
\hline \multicolumn{10}{|l|}{ Escherichia coli } \\
\hline Phase $1^{\mathrm{a}}$ & 9 & 0.0 & 0.0 & 0.0 & 0.0 & 0.0 & 11.1 & 0.0 & 88.9 \\
\hline Phase $2^{\mathrm{b}}$ & 10 & 20.0 & 20.0 & 10.0 & 0.0 & 0.0 & 10.0 & 0.0 & 50.0 \\
\hline \multicolumn{10}{|l|}{ Klebsiella species } \\
\hline Phase $1^{\mathrm{a}}$ & 4 & 66.7 & 33.3 & 50.0 & 0.0 & 0.0 & 50.0 & 0.0 & 75.0 \\
\hline Phase $2^{\mathrm{b}}$ & $18^{d}$ & 44.4 & 44.4 & 27.8 & 0.0 & 0.0 & 44.4 & 11.1 & 50.0 \\
\hline \multicolumn{10}{|l|}{ Proteus species } \\
\hline Phase $1^{\mathrm{a}}$ & 1 & 100.0 & 100.0 & $\ldots$ & 0.0 & 0.0 & $\ldots$ & 0.0 & 100.0 \\
\hline Phase $2^{b}$ & 6 & 50.0 & 16.7 & 0.0 & 0.0 & 0.0 & 0.0 & 0.0 & 33.3 \\
\hline \multicolumn{10}{|c|}{ Stenotrophomonas maltophilia } \\
\hline Phase $1^{\mathrm{a}}$ & 2 & $\ldots$ & $\ldots$ & 0.0 & $\ldots$ & $\ldots$ & $\ldots$ & $\ldots$ & $\ldots$ \\
\hline Phase $2^{b}$ & 4 & $\ldots$ & $\ldots$ & 0.0 & $\ldots$ & $\ldots$ & $\ldots$ & $\ldots$ & $\ldots$ \\
\hline \multicolumn{10}{|l|}{ Citrobacter } \\
\hline Phase $1^{\mathrm{a}}$ & 1 & 0.0 & 0.0 & 0.0 & 0.0 & 0.0 & 0.0 & 0.0 & 0.0 \\
\hline Phase $2^{b}$ & 2 & 0.0 & 0.0 & 0.0 & 0.0 & 0.0 & 0.0 & 0.0 & 0.0 \\
\hline \multicolumn{10}{|l|}{ Flavobacterium } \\
\hline Phase $1^{\mathrm{a}}$ & 0 & & & & & & & & \\
\hline Phase $2^{b}$ & 1 & 0.0 & 0.0 & 0.0 & 0.0 & 0.0 & 0.0 & 0.0 & 100.0 \\
\hline \multicolumn{10}{|c|}{ Haemophilus influenzae } \\
\hline Phase $1^{a}$ & 0 & & & & & & & & \\
\hline Phase $2^{b}$ & 3 & 0.0 & $\ldots$ & $\ldots$ & $\ldots$ & $\ldots$ & $\ldots$ & $\ldots$ & 0.0 \\
\hline \multicolumn{10}{|c|}{ Serratia marcescens } \\
\hline Phase $1^{a}$ & 0 & & & & & & & & \\
\hline Phase $2^{\mathrm{b}}$ & 3 & 33.3 & 33.3 & 33.3 & 0.0 & 0.0 & 33.3 & 0.0 & 33.3 \\
\hline \multicolumn{10}{|l|}{ Total } \\
\hline Phase $1^{\mathrm{a}}$ & 48 & 68.8 & 45.8 & $62.5^{\mathrm{e}}$ & 4.2 & 8.3 & 45.8 & 25.0 & 87.5 \\
\hline Phase $2^{b}$ & 64 & 39.1 & 37.5 & 20.3 & 9.4 & 9.4 & 29.7 & 7.8 & 54.7 \\
\hline
\end{tabular}

Note: CRO: ceftriaxone, CAZ: ceftazidime, CIP: ciprofloxacin, IMP: imipenem, MER: meropenem, GEN: gentamicin, AK: amikacin, AM/SB: ampicillin-sulbactam, .... not applicable.

a Without restriction, 1 May 2004 to 28 February 2005.

b With restriction, 1 May 2005 to 28 February 2006.

c $P<0.01$, phase 2 versus phase 1 .

d $P<0.05$, phase 2 versus phase 1 .

e $P=0.0557$, phase 2 versus phase 1 .

44) demonstrated that, in the absence of cross-colonization, the use of oxyiminocephalosporins fundamentally selected enterobacteria with class $C \beta$-lactamases on their chromosomes. In this sense, reduction in the use of ceftriaxone decreases selection pressure in Enterobacter spp. mutants that constitutionally express these enzymes. On the other hand, the increase in isolation of Klebsiella spp. and Proteus spp. could be related to increased cross-colonization.

The Kaplan-Maier method fails to significantly document that the day-by-day colonization or infection by r-GNB occurs at a later point in time in phase 2 . The Kaplan-Maier curve validates that, on day 10 of admission to the intensive care unit in both phases, $80.0 \%$ of the patients were free of $r-G N B$ colonization or infection. This percentage holds up to day 20 in phase 2, while on the same day in phase 1 it drops to $52.5 \%$.

The importance of this work lies in the fact that the impact is achieved with the use of a simple ceftriaxone and ciprofloxacin restriction policy, substituting them with similar spectrum mol- ecules such as ampicillin-sulbactam or aminoglycosides. Most research, after restricting ceftriaxone or ciprofloxacin, tends to replace them with cefepime, antipseudomonal penicillins, piperacillin-tazobactam, or even a carbapenem group $(20-21,45)$. However, the use of these types of molecules can have a negative impact on the change in susceptibility profile, as described by Rahal et al. (45), who achieved restricted use of ceftazidime through greater use of a carbapenem group, which in turn determined an increased resistance of $P$. aeruginosa to imipenem. The advantage of using ampicillin-sulbactam lies in its wide availability in different intensive care units, its cost-effectiveness, and the fact that its spectrum is similar to that of ceftriaxone but it has less impact on the bacterial ecology and a narrower spectrum than the alternatives used by other authors. Physicians, for example, when diagnosing a severe communityacquired pneumonia during phase 2, indicated ampicillin-sulbactam rather than ceftriaxone, which is supported by a Latin American consensus (46). Ampicillin-sulbactam was also used instead of ceftriaxone when treating other infections in which participation of nonmultiresistant GNB was suspected. This treatment did not expose patients to a higher risk, as evidenced by the similar length of hospital stays and mortality in both phases.

Unlike $\mathrm{Du}$ et al. (21), an impact on mortality during the postrestriction period was not achieved. This result can be explained in various ways. First, the sample is smaller. Second, the patient population is more severely ill, as shown by an Acute Physiology and Chronic Health Evaluation II (APACHE II) score of 21 versus 12.5 and a greater need for mechanical ventilation $(80.0 \%$ versus $53.4 \%$ ).

Some limitations of this study must be acknowledged. The sample size was small, according to the type of intensive care unit observed, but the statistical analysis was performed with specific tests for small samples. Another limitation is that colonizations were analyzed without having previously adopted a universal culture policy, which means the colonizations came from cultures of patients suspected of having an infection. Nevertheless, it should be emphasized that there was no intervention 
TABLE 5. Infections and colonizations with resistant Gram-negative bacilli in patients without and with restriction of antimicrobials, intensive care unit, Hospital Policial, Montevideo, Uruguay, 2004-2006

\begin{tabular}{|c|c|c|c|c|c|}
\hline & \multicolumn{2}{|c|}{ Phase $1^{a}$} & \multicolumn{2}{|c|}{ Phase $2^{b}$} & \multirow[b]{2}{*}{$P$ value } \\
\hline & No. & $\%$ & No. & $\%$ & \\
\hline Patients with r-GNB colonizations & 14 & $\ldots$ & 4 & $\ldots$ & 0.0006 \\
\hline Colonizations with r-GNB & 19 & $\ldots$ & 4 & $\ldots$ & $<0.0001$ \\
\hline r-GNB isolates of colonizations & 22 & $\ldots$ & 5 & $\ldots$ & 0.0001 \\
\hline Pseudomonas aeruginosa & 5 & 22.7 & 1 & 20.0 & 0.22 \\
\hline Acinetobacter baumannii & 11 & 50.0 & 1 & 20.0 & 0.0066 \\
\hline Stenotrophomonas maltophilia & 1 & 4.5 & 0 & $\ldots$ & 1.00 \\
\hline Enterobacteriaceae & 5 & 22.7 & 3 & 60.0 & 1.00 \\
\hline Patients with r-GNB nosocomial infections & 12 & $\ldots$ & 16 & $\ldots$ & 0.54 \\
\hline Infections with r-GNB & 12 & $\ldots$ & 20 & $\ldots$ & 0.65 \\
\hline r-GNB, number of isolates of infections & 14 & $\ldots$ & 22 & $\ldots$ & 0.61 \\
\hline Pseudomonas aeruginosa & 3 & 21.4 & 3 & 13.6 & 0.41 \\
\hline Acinetobacter baumannii & 2 & 14.3 & 2 & 9.1 & 0.60 \\
\hline Stenotrophomonas maltophilia & 1 & 7.1 & 4 & 18.2 & 0.65 \\
\hline Enterobacteriaceae & 8 & 57.1 & 13 & 59.1 & 0.78 \\
\hline
\end{tabular}

Note: r-GNB: resistant Gram-negative bacilli, ...: not applicable.

a Without restriction, 1 May 2004 to 28 February 2005.

b With restriction, 1 May 2005 to 282006 . during phase 2 from which to obtain further samples.

\section{Conclusions}

The restriction of ceftriaxone and ciprofloxacin reduces Acinetobacter spp. colonization and improves the susceptibility profile of $P$. aeruginosa by means of a simple protocol that uses low-cost antibiotics such as ampicillin-sulbactam that are widely available in intensive care units.

Acknowledgments. The authors thank Henry Albornoz and Rafael Vignoli for their exhaustive revision of the manuscript and their suggestions. This work was presented in part at the 47th Interscience Conference on Antimicrobial Agents and Chemotherapy, Chicago, 1720 September 2007.

\section{REFERENCES}

1. Lorente C, Del Castillo Y, Rello J. Prevention of infection in the intensive care unit: current advances and opportunities for the future. Curr Opin Crit Care. 2002;8(5):461-4.

2. Tenover FC, Hughes JM. The challenges of emerging infectious diseases. Development and spread of multiply-resistant bacterial pathogens. JAMA. 1996;275(4):300-4.

3. Hsueh PR, Teng LJ, Chen CY, Chen WH, Yu CJ, Ho SW, et al. Pandrug-resistant Acinetobacter baumannii causing nosocomial infections in a university hospital, Taiwan. Emerg Infect Dis. 2002;8(8):827-32.

4. Pellegrino FL, Teixeira LM, Carvalho Mda G, Aranha Nouér S, Pinto De Oliveira M, Mello Sampaio JL, et al. Occurrence of a multidrugresistant Pseudomonas aeruginosa clone in different hospitals in Rio de Janeiro, Brazil. J Clin Microbiol. 2002;40(7):2420-4.

5. Coque TM, Oliver A, Pérez-Díaz JC, Baquero F, Cantón R. Genes encoding TEM-4, SHV-2, and CTX-M-10 extended-spectrum betalactamases are carried by multiple Klebsiella pneumoniae clones in a single hospital (Madrid, 1989 to 2000). Antimicrob Agents Chemother. 2002;46(2):500-10.

6. Sanders WE Jr, Sanders CC. Enterobacter spp. pathogens poised to flourish at the turn of the century. Clin Microbiol Rev. 1997;10(2):220-41.

7. Cantón R, Oliver A, Coque TM, Varela M del C, Pérez-Díaz JC, Baquero F. Epidemiology of extended-spectrum beta-lactamase-producing Enterobacter isolates in a Spanish hospital during a 12-year period. J Clin Microbiol. 2002;40(4):1237-43.

8. Oplustil CP, Nunes R, Mendes C, RESISTNET Group. Multicenter evaluation of resistance patterns of Klebsiella pneumoniae, Escherichia coli, Salmonella spp. and Shigella spp. isolated from clini- cal specimens in Brazil: RESISTNET Surveillance Program. Braz J Infect Dis. 2001;5(1):8-12.

9. Trucco OA, Prado VJ, Durán TM, PRONARES Group. PRONARES antimicrobial surveillance network on antimicrobial agent resistance: report of the first semester 2001. Rev Chil Infect. 2002;19(Suppl 2):S140-8.

10. Sader HS, Jones RN, Gales AC, Silva JB, Pignatari AC, SENTRY Participants Group (Latin America). SENTRY antimicrobial surveillance program report: Latin American and Brazilian results for 1997 through 2001. Braz J Infect Dis. 2004;8(1):25-79.

11. Livermore DM. Beta-lactamases in laboratory and clinical resistance. Clin Microbiol Rev. 1995;8(4):557-84.

12. Massova I, Mobashery S. Kinship and diversification of bacterial penicillin-binding proteins and beta-lactamases. Antimicrob Agents Chemother. 1998;42(1):1-17.

13. Davies J. Inactivation of antibiotics and the dissemination of resistance genes. Science. 1994;264(5157):375-82.

14. Vignoli R, Calvelo E, Cordeiro NF, Lucero $\mathrm{R}$, Ingold $\mathrm{E}$, Quintana $\mathrm{A}$, et al. Association of broad-spectrum antibiotic use with faecal carriage of oxyiminocephalosporin-resistant Enterobacteriaceae in an intensive care unit. J Hosp Infect. 2006;63(3):306-15.

15. Medina J, Formento C, Pontet J, Curbelo A, Bazet C, Gerez J, et al. Prospective study of risk factors for ventilator-associated pneumonia caused by Acinetobacter species. J Crit Care. 2007;22(1):18-26.

16. Garner JS. Guideline for isolation precautions in hospitals. Part I. Evolution of isolation practices, Hospital Infection Control Practices Advisory Committee. Am J Infect Control. 1996:24(1):24-31.
17. Shlaes DM, Gerding DN, John JF Jr, Craig WA, Bornstein DL, Duncan RA, et al. Society for Healthcare Epidemiology of America and Infectious Diseases Society of America Joint Committee on the Prevention of Antimicrobial Resistance: guidelines for the prevention of antimicrobial resistance in hospitals. Infect Control Hosp Epidemiol. 1997;18(4):275-91.

18. Raymond DP, Pelletier SJ, Crabtree TD, Gleason TG, Hamm LL, Pruett TL, et al. Impact of a rotating empiric antibiotic schedule on infectious mortality in an intensive care unit. Crit Care Med. 2001;29(6):1101-8.

19. Gruson D, Hilbert G, Vargas F, Valentino R, Bebear C, Allery A, et al. Rotation and restricted use of antibiotics in a medical intensive care unit. Impact on the incidence of ventilator-associated pneumonia caused by antibiotic-resistant Gram-negative bacteria. Am J Respir Crit Care Med. 2000;162(3 Pt 1):837-43.

20. Gruson D, Hilbert G, Vargas F, Valentino R, Bui N, Pereyre S, et al. Strategy of antibiotic rotation: long-term effect on incidence and susceptibilities of Gram-negative bacilli responsible for ventilator-associated pneumonia. Crit Care Med. 2003;31(7):1908-14.

21. Du B, Chen D, Liu D, Long Y, Shi Y, Wang H, et al. Restriction of third-generation cephalosporin use decreases infection-related mortality. Crit Care Med. 2003;31(4):1088-93.

22. Knaus WA, Draper EA, Wagner DP, Zimmerman JE. APACHE II: a severity of disease classification system. Crit Care Med. 1985;13(10):818-29.

23. McCabe WR, Jackson GG. Gram-negative bacteremia. Arch Intern Med. 1962;110(6):847-55

24. Maxwell M, Heaney D, Howie JG, Noble S. General practice fund holding: observa- 
tions on prescribing patterns and costs using the defined daily dose method. BMJ. 1993;307(6913):1190-4.

25. National Nosocomial Infections Surveillance System. National Nosocomial Infections Surveillance (NNIS) System Report, data summary from January 1992 through June 2004, issued October 2004. Am J Infect Control. 2004;32(8):470-85.

26. National Committee for Clinical Laboratory Standards. Performance standards for antimicrobial susceptibility testing. Eleventh informational supplement NCCLS M100-S11. Wayne, Pennsylvania: Clinical and Laboratory Standards Institute; 2001.

27. Garner JS, Jarvis WR, Emori TG, Horan TC, Hughes JM. CDC definitions for nosocomial infections, 1988. Am J Infect Control. 1988;16(3):128-40.

28. Flanagan P, Findlay G, Magee J, Ionescu A, Barnes RA, Smithies M. The diagnosis of ventilator-associated pneumonia using nonbronchoscopic, non-directed lung lavages. Intensive Care Med. 2000;26(1):20-30.

29. Montravers P, Fagon JY, Chastre J, Lecso M, Dombret MC, Trouillet JL, et al. Follow-up protected specimen brushes to assess treatment in nosocomial pneumonia. Am Rev Respir Dis. 1993;147(1):38-44.

30. Bergmans DC, Bonten MJ, De Leeuw PW, Stobberingh EE. Reproducibility of quantitative cultures of endotracheal aspirates from mechanically ventilated patients. J Clin Microbiol. 1997;35(3):796-8.

31. Ortega B, Groeneveld AB, Schultsz C. Endemic multidrug-resistant Pseudomonas aeruginosa in critically ill patients. Infect Control Epidemiol. 2004;25(10):825-31.

32. Murthy R. Implementation of strategies to control antimicrobial resistance. Chest. 2001; 119(2 Suppl):405S-11S.
33. Raymond DP, Pelletier SJ, Crabtree TD, Evans HL, Pruett TL, Sawyer RG. Impact of antibiotic-resistant Gram-negative bacilli infections on outcome in hospitalized patients. Crit Care Med. 2003;31(4):1035-41.

34. Baumgartner JD, Glauser MP. Pharmacokinetic and microbial susceptibility studies of ceftriaxone. Eur J Clin Microbiol. 1983;2(5):501-4.

35. Patel IH, Chen S, Parsonnet M, Hackman MR, Brooks MA, Konikoff J, et al. Pharmacokinetics of ceftriaxone in humans. Antimicrob Agents Chemother. 1981;20(5):634-41.

36. Corbella X, Pujol M, Ayats J, Sendra M, Ardanuy C, Domínguez MA, et al. Relevance of digestive tract colonization in the epidemiology of nosocomial infections due to multiresistant Acinetobacter baumannii. Clin Infect Dis. 1996;23(2):329-34.

37. Aubert G, Carricajo A, Vautrin AC, Guyomarc'h S, Fonsale N, Page D, et al. Impact of restricting fluoroquinolone prescription on bacterial resistance in an intensive care unit. J Hosp Infect. 2005;59(2):83-9.

38. Neuhauser MM, Weinstein RA, Rydman R, Danziger LH, Karam G, Quinn JP. Antibiotic resistance among Gram-negative bacilli in US intensive care units: implications for fluoroquinolone use. JAMA. 2003;289(7): $885-8$

39. Friedland I, Gallagher G, King T, Woods GL. Antimicrobial susceptibility patterns in Pseudomonas aeruginosa: data from a multicenter Intensive Care Unit Surveillance Study (ISS) in the United States. J Chemother. 2004;16(5):437-41.

40. Kollef MH, Sherman G, Ward S, Fraser VJ. Inadequate antimicrobial treatment of infections: a risk factor for hospital mortality among critically ill patients. Chest. 1999;115(2):462-74.
41. Paterson DL. Restrictive antibiotic policies are appropriate in intensive care units. Crit Care Med. 2003;31(Suppl):S25-8.

42. Archibald LK, Manning ML, Bell LM, Banerjee S, Jarvis WR. Patient density, nurse-to-patient ratio and nosocomial infection risk in a pediatric cardiac intensive care unit. Pediatr Infect Dis J. 1997;16(11):1045-8.

43. Robert J, Fridkin SK, Blumberg HM, Anderson B, White N, Ray SM, et al. The influence of the composition of the nursing staff on primary bloodstream infection rates in a surgical intensive care unit. Infect Control Hosp Epidemiol. 2000;21(1):12-7.

44. Bado I, Cordeiro NF, Robino L, GarcíaFulqueiras V, Seija V, Bazet C, et al. Detection of class 1 and 2 integrons, extended-spectrum $\beta$-lactamases and qnr alleles in enterobacterial isolates from the digestive tract of intensive care unit inpatients. Int J Antimicrob Agents. 2010;36(5):453-8.

45. Rahal JJ, Urban C, Horn D, Freeman K, SegalMaurer S, Maurer J, et al. Class restriction of cephalosporin use to control total cephalosporin resistance in nosocomial Klebsiella. JAMA. 1998;280(14):1233-7.

46. Bantar C, Curcio D, Jasovich A, Bagnulo H, Arango A, Bavestrello L, et al. Neumonía aguda adquirida en la comunidad en adultos: actualización de los lineamientos para el tratamiento antimicrobiano inicial basado en la evidencia local del Grupo de Trabajo de Sudamérica (ConsenSur II). Rev Chilena Infectol. 2010;27(Suppl 1):S9-38.

Manuscript received on 2 March 2011. Revised version accepted for publication on 31 October 2011.

RESUMEN Objetivo. Determinar si la restricción del uso de ceftriaxona y ciprofloxacino reduce significativamente la colonización y la infección por bacilos gramnegativos resistentes. Métodos. Se efectuó un estudio prospectivo de dos fases (diseño antes/después

Restricción del uso de ceftriaxona y ciprofloxacino en una unidad de cuidados intensivos: menor incidencia de Acinetobacter spp. y mayor sensibilidad de Pseudomonas aeruginosa

Palabras clave de la intervención) en una unidad de cuidados intensivos en dos períodos sucesivos entre los años 2004 y 2006. Durante la fase 1, no hubo ninguna restricción de antibióticos. Durante la fase 2, se restringió el uso de ceftriaxona y ciprofloxacino.

Resultados. Se evaluó prospectivamente a 200 pacientes en total. En la fase 2, el uso de ceftriaxona se redujo en $93,6 \%(P=0,0001)$ y el de ciprofloxacino en $65,1 \%(P=0,041)$, lo que se acompañó de un aumento de $113,8 \%$ en el uso de ampicilina/sulbactam $(P=0,002)$. Durante la fase 1 , se aislaron 48 bacilos gramnegativos (37 resistentes $[77,1 \%]$ y 11 no resistentes [22,9\%]), en comparación con un total de 64 durante la fase 2 (27 resistentes $[42,2 \%]$ y 37 no resistentes $[57,8 \%])(P=0,0002)$. Se aisló Acinetobacter spp. 13 veces durante la fase 1 y 3 veces en la fase $2(P=0,0018)$. La sensibilidad de Pseudomonas aeruginosa al ciprofloxacino aumentó de 40,0\% en la fase 1 a 100,0\% en la fase $2(P=0,0108)$.

Conclusiones. La restricción del uso de ceftriaxona y ciprofloxacino redujo la colonización por Acinetobacter spp. y mejoró el perfil de sensibilidad de P. aeruginosa.

Resistencia a múltiples medicamentos; Acinetobacter baumannii; Pseudomonas aeruginosa; agentes antibacterianos; Uruguay. 